the White House, the mix of technological exuberance and triumphalism, born of the United States' superiority in space, started to challenge the old paradigm of space security based on an international legal regime. The first signal of change came in January 2001 from a US commission on space security, chaired by Donald Rumsfeld before he became defence secretary. Warning that the United States could one day face a "space Pearl Harbor" - a devastating surprise attack on its strategically important space assets - the commission members wanted to ensure "that the President will have the option to deploy weapons in space to deter threats to, and if necessary, defend against attacks on US interests".

Rumsfeld presided over several Pentagon activities that prepared arguments for the full-spectrum use of force in space. Thus, the Air Force Space Command described in its 2004 Strategic Master Plan the possibility of using anti-satellite weapons, or even weapons that could be deployed in space to target objects on Earth. Most controversial was the US withdrawal in 2001 from the international Antiballistic Missile Treaty, which had by then been in force for three decades.

The existing set of space laws has loopholes. It does not restrict conventional weapons in space that could destroy or damage orbiting satellites. Satellites are extremely vulnerable even to primitive attacks, such as being hit at high speed by a projectile, and anti-satellite weapons exploit this fragility. Such weapons were not added to military arsenals during the cold war. However, both sides have kept open the possibility of developing these weapons to gain superiority, while each fearing that the other will overtake technologically.

To close these loopholes, experts are calling for the introduction of 'rules of the road' for orbital traffic, the prohibition of all weapons in space, the testing and deployment of antisatellite weapons on the ground and support for international arrangements to mitigate the growing risk from space debris to assets in orbit.

China and Russia, for example, have tried during the past few years to introduce an initiative to ban space weapons in the UN Conference on Disarmament. The United States, with almost a lone voice, has blocked this discussion. China's test of an anti-satellite weapon in 2007 increased the pressure to act, and demonstrated that not everyone is ready to accept the space dominance of one country.

The collision in February this year of an active US telecommunications satellite from the Iridium constellation with a long-dead Russian one adds an alarm call. Introducing regulations that require satellites to be de-orbited at the end of their active life would need international cooperation and exchange of information on orbital traffic and debris. As with military threats, the United States has most to lose in an unregulated environment because it has the greatest presence in space.

A regulatory regime for orbiting objects can be introduced in various ways. An international law to ban space weapons, adopted by the UN, would offer a radical solution. In the interim, a regime of restraint could be agreed among those countries that are active in space. A precedent is the Missile Technology Control Regime - a voluntary association of 34 countries that has been promoted by the United States and others since the end of the cold war. Governments could also pledge not to place weapons in orbit.

Moltz ends on a pessimistic note: the long and difficult political battle to come. Proponents of space-based weaponry point to risks from North Korea, a nation seemingly embracing both nuclear weapons and seeking orbital capability. Iran's nuclear and rocket development is cited as another potential threat. However, the debate is changing thanks to the rapid rise of civilian space applications.
Satellite networks for telecommunications, remote sensing and navigation are effectively global utilities. Space exploration today is also largely carried out by international collaboration, whether the mission is to Mars or the Moon. The presence of the International Space Station, which brought together the former adversaries of the cold war, itself safeguards against space becoming a battleground.

The rise of Barack Obama to the highest political orbit brings new hope. Promises he made during his presidential campaign include pursuing international negotiations to minimize space debris and banning the weaponization of space. He has declared that "the United States must show leadership by engaging other nations in discussions of how best to stop the slow slide towards a new battlefield". Such leadership is urgently needed.

Roald Sagdeev is a Distinguished University Professor of physics and director of the East West Science Center at the University of Maryland, College Park, Maryland 20742, USA. He was director of the Russian Space Research Institute (1973-88) and science adviser to Mikhail Gorbachev (1985-88).

e-mail: rsagdeev@gmail.com

\title{
The return path to the Moon
}

\section{The Seventh Landing: Going Back to the Moon, This Time to Stay by Michael Carroll Springer: 2009.115 pp. $£ 19.99, \$ 29.95$}

In The Seventh Landing, Michael Carroll adeptly lays out NASA's strategy for returning to the Moon, establishing a permanent outpost there, and, if all goes well, pushing on to Mars. It is a complex and ambitious undertaking, requiring a new fleet of launch vehicles, an updated crew module, a more versatile lunar lander, sophisticated all-terrain vehicles, souped-up spacesuits, lunar habitats and enough acronyms to make your head explode. Fortunately, using straightforward reportage, coupled with his own stunning space art, Carroll brings compelling order to what could have been a chaotic romp.

NASA's goal is to get moon boots on lunar soil by the year 2020 . But to do so, milestones must be passed on schedule. The maiden flight of the booster rocket, Ares I, which will loft the crew module, Orion, into orbit, is scheduled for early 2013. Orion, which will accommodate a crew of up to six, may fly its first manned mission to the International Space Station by 2015. The more powerful Ares V booster will carry the lunar lander, named Altair, into Earth orbit. After docking with the crew module, the booster's upper stage will haul both Orion and Altair to the Moon. Ares V's maiden flight is scheduled for 2018. Deadlines, hardware and mission details are in flux but, Carroll recognizes, "the overarching goals, strategies and inspiration for the seventh landing will not change".

Those sentiments, however, may not go unsullied. Even now, under a directive by US President Barack Obama, a committee of ten aerospace executives, astronauts, engineers, scientists and a retired general are taking a down-to-earth look at the United States' space exploration strategies (Nature 459, 1038-1039; 2009). Particularly sobering are the budget constraints on completing both the Orion module and the Ares V booster. Reservations from scientists about the value of a return to the Moon have also reached the committee's ears. Their report, which chairman Norman Augustine asserts will be unblinking in its findings, will be released in August.

After looking back at early robotic lunar missions such as the Luna and Ranger series and then the Apollo programme, Carroll shifts the focus from our lunar history to our potential lunar future and the justification for that 
future. Whereas the Mercury, Gemini and Apollo programmes were politically motivated, the reasons to return are more practical. Jim Garvin, chief scientist at NASA's Goddard Space Flight Center in Greenbelt, Maryland, gives the most succinct reason: "Going to the Moon enables us to build a platform for technology that is transformational to our society, and that's not just Teflon."

As Carroll's interviews with experts show, those of us who remain on Earth will probably reap the benefits from innovations that emerge from the new Moon programme. These include advances in communications, materials science, computer technology, robotics, medical procedures and even building materials.

There are also purely scientific reasons for returning to the Moon. It is, as Carroll writes, "the Rosetta stone of the terrestrial planets", and there is still much to be learned about its geology and origins. If ice is locked up in the permanently shadowed regolith at the north or south poles, as many scientists think, it probably got there via countless impacting comets. Such material would be pristine, deposited when the Solar System was in its infancy. A study of these volatiles would prove invaluable to understanding the origins of the Solar System.

Inherent in the strategy is the long-range vision of sending humans to work and live on Mars. If we can learn to abide in a lunar environment, we should be able to deal with the harsh conditions on the Red Planet. As Carroll

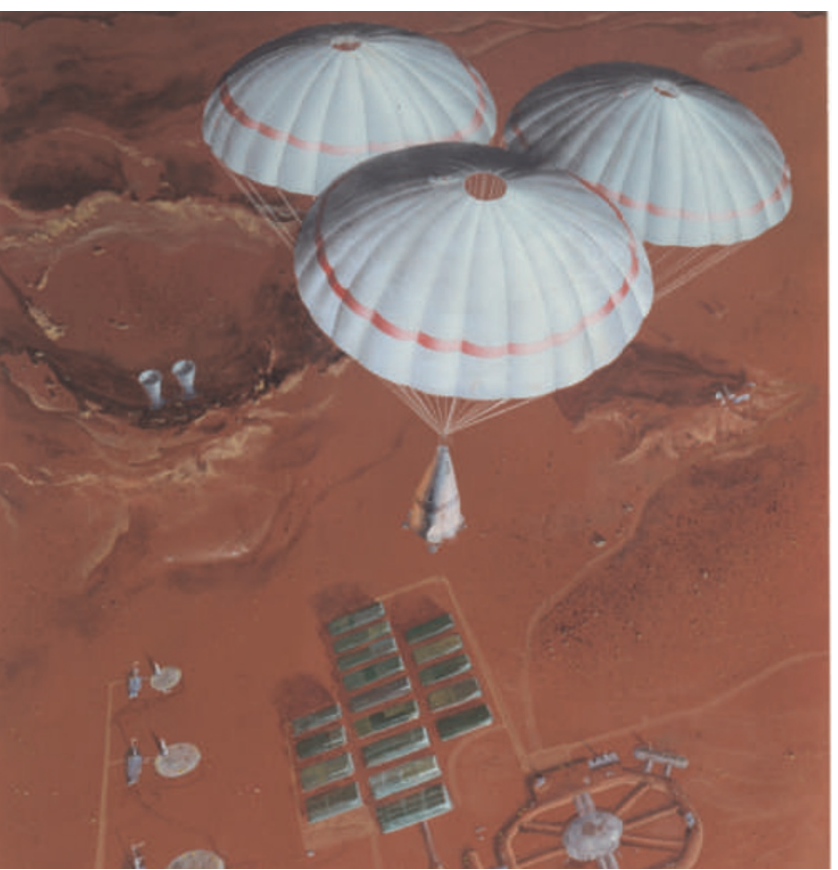

reach a favourable alignment for the journey back.

Planetary scientist Chris McKay of NASA's Ames Research Center in Moffett Field, California, thinks our approach should resemble the efforts made to live and work in Antarctica. "We've been [in Antarctica] for 50 years and built a station that's designed to last at least another 30 . That's the kind of mentality I would like infused into the Moon programme ... and Mars base."

Carroll writes passionately that missions to the Moon and Mars are like instinctual siren calls to humans. "It is something larger than ourselves, something for the generations to come." To deny these instincts, he argues, is to deny our history and to deny our humanity.

Having won the race to the Moon with Apollo 11 in 1969, US public interest in pushing on to Mars quickly waned. The Seventh Landing demonstrates that it has never died,

describes, however, many in the aerospace industry ask: why waste time and money on the Moon when those resources could be better used for a mission to Mars? This debate will not be settled for some time.

What is not up for debate is the difficulty of establishing a long-term base on Mars. Just getting humans there will be a challenge. Travel times will be up to eight months, and by the time a crew lands the launch window to return home will practically be gone. Even if a crew stays for only a few weeks, they would have to wait another year and a half for the planets to however. Carroll's enthusiasm is infectious and will inspire readers who look back on the the Apollo landings as a time when mankind really did make giant leaps towards a promising future. Maybe we will finish what we started 40 years ago and set a course for Mars, either directly, or by way of the Moon. After all, that was the idea in the first place.

Jeff Kanipe is the author of Cosmic Connection: How Astronomical Events Impact Life on Earth. He lives in the Washington $D C$ region. e-mail: jeff.kanipe@comcast.net For more on Apollo, see www.nature.com/Apollo.

\section{APC
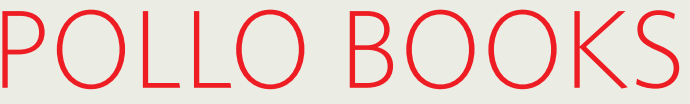

The anniversary of the first footstep on the Moon is being celebrated in an array of new books. Drawing on NASA's archive of oral histories, and declassified Central Intelligence

Agency material on the space race, historian Craig Nelson tells in Rocket Men (Viking) the full story of the Apollo programme from the crews' training to the first moonwalkers' return as media stars.

In his straight-talking memoir Magnificent Desolation (Harmony), co-written with author Ken Abraham, Buzz Aldrin describes the great journey. More than 600 million people watched Aldrin become the second man to set foot on the Moon. But on his return to Earth he spiralled into depression and alcoholism.

Other Apollo astronauts describe their lunar experiences in Andrew Chaikin's Voices From the Moon (Viking Studio) and select their favourite photographs from the mission in Apollo: Through the Eyes of the Astronauts (Abrams), edited by Robert Jacobs and others. NASA's official history, Apollo
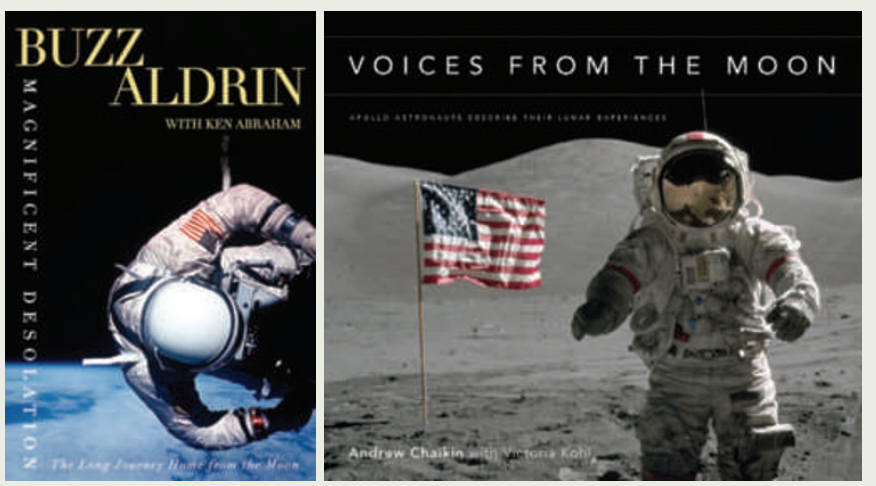

A shelf of testimonies from the men who walked the walk.

Expeditions to the Moon, edited by Edgar Cortright, is being reissued by Dover. It will include first-hand accounts from those involved in all areas of the mission and a DVD with historic space footage. 